\title{
Prevalence of and Factors Associated with Emergency Contraceptive Use among Female Undergraduates in Arba Minch University, Southern Ethiopia, 2015: A Cross-Sectional Study
}

\author{
Yohannes Ayanaw Habitu (iD, ${ }^{1}$ Hedija Yenus Yeshita, ${ }^{1}$ \\ Abel Fekadu Dadi, ${ }^{2}$ and Desta Galcha ${ }^{3}$ \\ ${ }^{1}$ Department of Reproductive Health, College of Medicine and Health Sciences, University of Gondar, Gondar, Ethiopia \\ ${ }^{2}$ Department of Epidemiology and Biostatistics, College of Medicine and Health Sciences, University of Gondar, Gondar, Ethiopia \\ ${ }^{3}$ Department of Surgery, College of Health Sciences, Addis Ababa University, Addis Ababa, Ethiopia
}

Correspondence should be addressed to Yohannes Ayanaw Habitu; yohaneshabitu@gmail.com

Received 8 August 2017; Revised 24 November 2017; Accepted 18 December 2017; Published 23 January 2018

Academic Editor: Sally Guttmacher

Copyright (C) 2018 Yohannes Ayanaw Habitu et al. This is an open access article distributed under the Creative Commons Attribution License, which permits unrestricted use, distribution, and reproduction in any medium, provided the original work is properly cited.

Emergency contraceptives (ECs) need to be available and used appropriately as a backup in case regular contraception is not taken by people like university students. This study was conducted to assess emergency contraception use and its associated factors among female undergraduates of Arba Minch University. A cross-sectional study was conducted among 515 undergraduates using a structured questionnaire. Respondents were selected by the stratified random sampling technique and data were analyzed using SPSS version 20. Bivariate and multivariate logistic regression models were fitted to identify associated factors. The adjusted odds ratio with a $95 \%$ confidence interval was used to present the identified risk factors. The prevalence of emergency contraception use among Arba Minch University students was 78.0\% (95\% CI: 71.5\%, 84.5\%). Better information about emergency contraceptives $(\mathrm{AOR}=6.3 ; 95 \% \mathrm{CI}: 2.4,9.7)$, good approach of EC service providers (AOR = 9.3; 95\% CI: 2.4, 11.6), and positive attitude about ECs $(A O R=2.4 ; 95 \%$ CI: $1.5,7.2)$ were factors significantly associated with EC use. The prevalence of emergency contraceptive use noted in this study was comparatively higher than the results found by previous studies conducted in Africa and Ethiopian universities. Continuing support for and wider dissemination of the class are recommended. The fact that the students/participants readily accepted the preceding provisions made such positive findings possible and sustainable.

\section{Introduction}

Over 100 million acts of sexual intercourse take place each day in the world, resulting in around 3 million conceptions of which $50 \%$ are unplanned and $25 \%$ definitely unwanted [1]. Unintended pregnancy is a global concern with far-reaching implications [2]. An estimated $26 \%$ of all pregnancies worldwide are terminated by induced abortions [3]: $41 \%$ in developed and $23 \%$ in developing regions $[4,5]$. Of the estimated 76 million unintended pregnancies that occur annually in developing countries, 34 million result in unplanned births. An estimated 10 million of the rest end in miscarriages, while 32 million are interrupted by induced abortion $[4,6]$.
This could have been averted if women had had access to maintenance and emergency contraceptives (EC).

A systematic review of the causes of maternal mortality estimated that unsafe abortion accounted for $13 \%$ of all maternal deaths in Africa [6,7]. Studies conducted in Ethiopia have shown that unsafe abortion accounts for $32 \%$ of maternal deaths [8]. Although unsafe abortions are preventable through sexuality education, family planning, and the provision of safe and legal abortion care services, they still continue to endanger the lives of many women.

Adolescent girls face a high risk of unintended pregnancies and unsafe abortions with devastating consequences on their health and life [5, 9]. Preventable deaths from 
improperly performed procedures (unsafe abortion) constitute $13 \%$ of the maternal mortality globally and $25 \%$ or more in some countries where maternal mortality from other causes is relatively low (e.g., Eastern Europe and South America), making unsafe abortion one of the leading causes of maternal mortality worldwide [5]. In Ethiopia, according to the survey conducted by the Ethiopian Society of Obstetricians and Gynecologists (ESOG) in nine administrative regions, $25.6 \%$ of the 1,075 abortion cases were induced abortions, of which $58 \%$ were girls in the age range of $20-29$ years. Of the pregnancies which ended in abortions, $60 \%$ were unplanned and 50\% unwanted [10].

The Ethiopian Parliament amended the penal code on abortion in 2005. The new law has improved access to safe abortion care by expanding the legal indications [11]. According to the amended law, safe abortion can be performed legally in cases of rape or incest, or if the women have physical or mental disabilities, or if it is needed to preserve the woman's life or physical health, or if she is a minor who is physically or mentally unprepared for childbirth [11]. The reforms were intended to prevent unsafe abortion through the expansion of safe abortion services throughout the healthcare system [11]. The reforms are widely accepted by healthcare providers. Now there are many healthcare providers (doctors, midwives, and nurses) trained to provide safe abortion services when women come to healthcare facilities in the above circumstances [8].

Emergency contraceptive is a type of modern contraception administered after unprotected sexual intercourse which plays a vital role in preventing unintended pregnancy, unsafe abortion, and unintended childbirth which are the major problems of maternal health [10]. In Ethiopia, the need for ECs was identified in the late 1990s. In 2001, the Family Guidance Association of Ethiopia (FGAE) in collaboration with the Population Council initiated ECs in selected youth center clinics in the country and the study area. In this project, ECs were provided in a repackaged brand so it would appeal to adolescents and youth in several ways, for example, by cutting the cost of the regular contraceptive pill, though the services were limited in scope and coverage [10].

In Ethiopia, the most common method of EC involves taking postcoital pills as soon as possible, optimally within 72 hours after unprotected sex. A second dose is taken 12 hours later. The insertion of an intrauterine device (IUD) within 5 days of unprotected sex is another less frequently used method of ECs [10]. Although IUDs are very effective, and their use is appropriate for many women, pills are easier to administer and are taken by the wider user group [12]. Emergency contraception is available without prescriptions from pharmacies [13], and it is provided free of charge in government health facilities and costs around 20 ETB (0.87 USD) in private stores.

Previous studies conducted in Nepal, Ghana, South Africa, and Nigeria showed that the level of EC utilization among female undergraduates was 8.4\% [14], 40\% [15], 21.2\% [16], and 37.9\% [17], respectively. Different studies conducted in Ethiopia showed that the level of EC utilization among female undergraduates was $11.1 \%$ in Adwa [18], 26.7\% at Adama University [19], 4.9\% at AAU in 2007 [20] and 9.3\% in
2012 [21], 75\% in Mekelle [21], 24.2\% in the Ethiopian Immigration and Nationality Affairs Office [22], 10.8\%, at Hawassa University [23], and 44.4\% at Wachamo University [24].

International and national evidences regarding factors associated with EC use showed that age [14, 16, 19, 23, 25], educational level [14], knowledge of ECs [22, 24, 26], culture $[15]$, religion $[15,18,24]$, sexual activity $[16,17]$, previous use of regular contraceptives [17-19], and marital status [19, 2426] were identified as factors associated with EC use by the earlier studies.

Evidence further showed that university students have history of different risky sexual behaviors that exposed female undergraduates to unintended pregnancy [27-29]. Due to the occurrence of unintended pregnancy, many university students are seeking induced abortion care [28-30]. EC is designed to prevent unintended pregnancy that may occur after performing casual or unprotected sex [28-30]. So it is very important to study the prevalence of and factors associated with the use of ECs among university students in order to design appropriate preventive interventions. Unlike studies conducted at the global level, those in Ethiopia contained marked disparities in the rate of EC utilization and its associated factors. Hence, it is difficult to conclude the rate of EC use among female undergraduates in particular settings in the Ethiopian context. The hypothesis is that the prevalence of EC use may be high and factors associated with EC use may not be similar to those of other studies. Conducting this research on the topic of EC use and associated factors at Arba Minch University (AMU) is assumed to be relevant for Sexual and Reproductive Health (SRH) policy formulation in the specific setup.

\section{Methods}

2.1. Study Design and Setting. The institution based crosssectional study was carried out to assess the prevalence of and factors associated with EC use among female undergraduates of AMU. The study was conducted on Arba Minch University female undergraduate students in October 2015. Arba Minch University is one of the most well-established universities found in Southern Nations, Nationalities, and People's Region. It is located in Arba Minch town $500 \mathrm{~km}$ south of Addis Ababa. The main campus of the university is situated at the eastern foot of Gamo mountain ranges adjacent to the vast lowland stretching towards lakes Abaya and Chamo which are part of the East African Rift Valley system. In the 2014/2015 academic years, a total of 16, 520 students were enrolled in the regular programs of which 4,741 (28.7\%) were females. In the undergraduate programs, women constitute $12.4 \%$ of the student population at the moment [31].

2.2. Source and Study Population. All AMU undergraduate female students and all such students who were available on campus during data collection were the source and the study population of this work. Students who were sick and unable to communicate during data collection were excluded.

2.3. Sample Size and Sampling Procedure. The sample size was calculated using the single population proportion formula, 
assuming a 95\% level of confidence interval, 0.05 margin of error, and the proportion of emergency contraception use to be $72.0 \%$ [21]. Finally, after adding a $10 \%$ nonresponse rate to the calculated sample size, the target sample size was 534. Stratified and random sampling procedures were used to select study participants. First, the students were stratified into two strata: health science and non-health science strata. We divided these two strata into their respective departments. After getting the list of students from each department, we allocated the calculated sample size to each department proportionally. Using the list of students from each department, participants were selected by a computer-generated simple random sampling technique. Finally, the questionnaire was distributed to students who were selected by the simple random sampling technique after arranging a separate room to keep them comfortable.

2.4. Study Variables. The outcome variable of this study was EC use, and the independent variables were students grouped under sociodemographic characteristics, knowledge, practice, and attitude towards emergency contraceptives. The dependent variable was dichotomized as "yes" or "no." Sociodemographic variables were collected using questions about the following: the age of the students which is divided into three groups as $18-20,21-25$, and $>=25$ years; religion as Orthodox, Protestant, Muslim, and others; campus as health science and non-health science; year of study as first year, second year, third year, and fourth year; residence as on campus and out of campus; history of previous residence as urban or rural; ethnicity as Amhara, Oromo, Tigray, and others; sexual and reproductive health history as age (in years) at menarche; age at first sex and history of sexual exposure as yes or no; history of condition of first sexual exposure as wanted (with consent) or unwanted; history of contraceptive use at first sex as "yes" or "no"; history of previous exposure to pregnancy as "yes" or "no"; history of previous EC use as "yes" or "no"; history of approach by EC service provider as "yes" or "no"; history of induced abortion as "yes" or "no"; marital status as married, divorced, separated, and widowed; mother's and father's educational status as being illiterate, primary school graduate, high school graduate, and higher education graduate; cultural acceptance of EC use as "yes" or "no"; religious acceptance of EC use as "yes" or "no"; information about EC as "yes" or "no"; students' attitudes towards "EC free of charge could increase the rate of its utilization" as "yes" or "no"; students' attitudes towards "EC is much better than the regular contraceptive methods for preventing unintended pregnancy." We determined knowledge about ECPs using four multiple-choice questions. Each correct answer was worth corresponding 1 point, that is, 4 points for the four questions. Students were considered to have enough knowledge if they scored above the mean. They were considered not to have enough knowledge if they scored below the mean. The students' attitudes were measured using seven items rated on a threepoint Likert scale as (1) agree, (2) neutral, and (3) disagree. Students were considered to have positive attitude if they scored above the mean and negative attitude if they scored below the mean.
2.5. Data Collection Instruments, Procedures, and Quality Assurance. A pretested semistructured and selfadministered questionnaire written in English was used to collect data. A pretest was administered on $5 \%$ of the calculated sample and appropriate modifications were made. Four female B.S. graduate nurses facilitated the process. Additionally, one male supervisor was recruited to supervise the data collection process. The instructors of the colleges were requested to allow us to use the last 20 minutes of their respective classes administering the questionnaire. After obtaining the written consent of respondents, then data were collected by the facilitators from October 15-30, 2015, under the follow-up of a trained supervisor and the principal investigator for accuracy and completeness. The questionnaire was distributed to the students randomly after proportionally stratifying them as health science and non-health science groups. The supervisor explained points that needed clarifications in the process of completing the forms and checked copies to correct errors on the spot.

2.6. Data Management. In addition to the checkups by the supervisor, all data were manually cleaned, checked, and coded by the principal investigator, in order to maximize the quality of the research. Data from the survey was entered into Epi info version 3.5 and exported to Statistical Package for Social Sciences (SPSS) version 20 software for further analysis. Descriptive statistics were presented using tables, graphs, charts, and frequencies. Variables with $<0.2 P$ values in the bivariate analysis were further entered into the multivariate model in order to see the presence of possible associations with the outcome variable. Variables with a $P$ value of $<0.05$ in the multivariate model were taken as significantly associated with the outcome variable at $95 \% \mathrm{CI}$.

2.7. Ethical Considerations. Ethical clearance was obtained from the Institutional Review Board (IRB) of UoG, College of Medicine and Health Sciences (CMHS), Institute of Public Health. Research permission was obtained from AMU and respective colleges before data collection. The participants were informed about the purpose of the study and the importance of their participation. Respondents were told that they could skip a question/s that they did not want to answer fully or partly and to quit the process at any time they wanted and that their participation was voluntary. After assuring confidentiality of and obtaining the informed consent of participants, copies were distributed to the undergraduate female students in their respective classes under strict secrecy. Participants' privacy was insured by avoiding personal identifiers, by separate seats, and by locking copies to limit data accessibility to a third party.

\section{Results}

3.1. Sociodemographic Characteristics of the Respondents. A total of five hundred and fifteen female students from Arba Minch University participated in the study with a response rate of $96.4 \%$. The majority of the respondents, $372(72.2 \%)$, were from urban areas, while Amhara and Oromo, the major 
ethnic groups, were 191 (37\%) and 113 (22\%), respectively. Three hundred and eleven (60.4\%) of the participants were Orthodox Christians, the majority, 449 (87.2\%), are unmarried at the moment, and $444(86.2 \%)$ belonged to non-health science fields. Four hundred and seventy-four (92\%) of the students were living on campus; 154 (29.9\%) and 152 (29.5\%) were first- and third-year students, respectively. Regarding parental educational status, $166(32.2 \%)$ of the respondents' mothers attended primary school, while 135 (26.2\%) of the fathers had higher education (Table 1).

3.2. Sexual and Reproductive History. Over half (58.3\%) of the participants reported that they had their periods when they were above 14 years of age. Regarding past sexual history, 200 (38.8\%) had sexual intercourse, 175 (87.5\%) of them fall in love and desired to practice sexual intercourse, and 32 (16\%) were exposed to pregnancy, 16 (50\%) of which ended in induced abortions.

3.3. Knowledge and Use of Emergency Contraceptives. More than two-thirds (63\%) of the respondents reported that they have heard about emergency contraceptive methods, and 148 $(28.7 \%)$ and 17 (3\%) mentioned oral contraceptive pills and IUDs as EC methods, respectively. Of those who had sexual intercourse, $156(78.0 \%)$ used EC methods. Out of the total participants, 301 (58.4\%) had good knowledge about ECs. When participants were asked about the purpose of ECs, 296 (57.5\%) said that ECs were used to prevent pregnancy after unprotected sexual intercourse; 265 (51.5\%) knew the timing of ECs; 312 (60.6\%) knew the side effects of ECs; 37 (70.2\%) knew sources of ECs; 301 (58.5\%) said ECs should not be used by pregnant woman; and 302 (58.6\%) stated that EC pills should not be used regularly like other contraceptive pills.

3.4. Attitude of Female Students of Arba Minch University towards Emergency Contraception. Out of the total participants, $243(47.3 \%)$ had a positive attitude, while $272(52.7 \%)$ had a negative attitude towards the use of ECs to prevent unintended pregnancy.

3.5. Access and Services of Emergency Contraception. Out of the students who used ECs, 52 (33.4\%) had the service from pharmacies and 17 (10.9\%) from hospitals. Sixty-nine $(44.23 \%)$ of EC users paid for the service they received. The majority, 349 (67.8\%), thought that getting ECs for free would increase the rate of its utilization. Long distance from health facilities and mistreatment by service providers were the two main barriers which prevented getting treatment for $63(44.5 \%)$ and 85 (54.4\%), respectively.

3.6. Factors Associated with EC Use among Female Arba Minch University Students. Seven variables, such as information about ECs, cultural acceptance of ECs, sexual intercourse by agreement, getting pregnant after sex, treatment by service providers, free ECs, and attitude towards ECs, had $P$ values of $<0.2$ in the bivariate logistic regression model. These variables were entered into the multivariate model to rule out the effects of possible confounders. Finally, factors like awareness
TABLE 1: Sociodemographic characteristics of female undergraduates of Arba Minch University, 2015.

\begin{tabular}{lcc}
\hline Variables & Frequency & Percent \\
\hline Age (515) & 176 & \\
$18-20$ & 324 & 34.2 \\
$21-25$ & 15 & 62.9 \\
$>25$ & & 2.9 \\
Mother's educational status (515) & 121 & \\
$\quad$ Illiterate & 167 & 23.5 \\
Primary school & 135 & 32.4 \\
High school & 92 & 26.2 \\
$\quad$ Higher education & & 17.9 \\
Father's educational status (515) & 75 & \\
Illiterate & 119 & 14.6 \\
Primary school & 119 & 23.1 \\
High school & 202 & 23.1 \\
Higher education & & 39.2 \\
Cultural acceptance of ECs (515) & 283 & \\
$\quad$ Yes & 232 & 55.0 \\
No & & 45.0 \\
Religion acceptance of ECs (515) & 184 & 35.7 \\
Yes & 331 & 64.3 \\
No & & \\
\hline
\end{tabular}

about ECs, treatment approach of service providers, and attitude towards ECs showed significant associations with EC use in the multivariate logistic regression model with $P$ values of $<0.05$.

Utilization was higher among participants who had information about ECs than those who had not [AOR $(95 \% \mathrm{CI})=$ $6.3(2.4,9.7)]$. Participants who were well approached by EC service providers were nine times more likely to use ECs than those who were mistreated $[\mathrm{AOR}(95 \% \mathrm{CI})=9.3(2.4,11.6)]$. Those who believed that taking ECs after unprotected sex was much better than the regular use of contraceptive methods to prevent unintended pregnancies were two times more likely to use ECs compared to those who did not believe in that $[\operatorname{AOR}(95 \% \mathrm{CI})=2.4(1.5,7.2)]($ Table 2$)$.

\section{Discussion}

This study assessed the prevalence of and factors associated with EC use among female undergraduate students at Arba Minch University. Of the sexually active students, slightly more than three-fourths used EC methods. Factors like having information about ECs, treatment approach of health care providers, and attitude towards ECs were significantly associated with EC utilization. This finding is similar to that of a study conducted at Addis Ababa University on Ethiopian female undergraduates which reported that 75\% used ECs [21].

This result is higher than those of other studies conducted in African countries, like South Africa 21.2\% [16], Nigeria $37.9 \%$ [17], and Ghana 39.9\% [15]. This difference could be due to the presence of some differences in sociodemographic 
TABLE 2: Showing determinants of EC utilization among female undergraduates of Arba Minch University, 2015.

\begin{tabular}{|c|c|c|c|c|}
\hline \multirow[b]{2}{*}{ Factors } & \multicolumn{2}{|c|}{ EC utilization } & \multirow{2}{*}{$\begin{array}{l}\text { COR }(95 \% \\
\text { CI })\end{array}$} & \multirow[b]{2}{*}{$\operatorname{AOR}(95 \% \mathrm{CI})$} \\
\hline & $\begin{array}{c}\text { Yes } \\
N(\%)\end{array}$ & $\begin{array}{c}\text { No } \\
N(\%)\end{array}$ & & \\
\hline \multicolumn{5}{|c|}{ Cultural acceptance of ECs (515) } \\
\hline Yes & $234(82.8)$ & $49(17.2)$ & 1 & 1 \\
\hline No & $183(79.0)$ & $49(21.0)$ & $1.3(0.7,2.1)$ & $0.9(0.2,3.3)$ \\
\hline \multicolumn{5}{|c|}{ Information about ECs (515) } \\
\hline No & $33(17.1)$ & $157(82.9)$ & 1 & 1 \\
\hline Yes & $307(94.3)$ & $18(5.7)$ & $\begin{array}{c}0.02(0.01 \\
2.60)\end{array}$ & $6.3(2.4,9.7)^{* *}$ \\
\hline \multicolumn{5}{|c|}{ Was the sex performed with consent (wanted sex) (200) } \\
\hline Yes & $143(81.7)$ & $32(18.3)$ & 1 & 1 \\
\hline No & $13(52)$ & $12(48)$ & $4.1(1.7,9.8)$ & $4.6(0.9,22.4)$ \\
\hline \multicolumn{5}{|c|}{ Ever got pregnant after sex (200) } \\
\hline Yes & $21(65.6)$ & $11(34.4)$ & 1 & 1 \\
\hline No & $135(81.5)$ & $33(18.5)$ & $0.5(0.2,1.0)$ & $1.9(0.3,9.8)$ \\
\hline \multicolumn{5}{|c|}{ Had history of well approach by EC service provider (515) } \\
\hline No & $34(39.9)$ & $51(60.1)$ & 1 & 1 \\
\hline Yes & $260(60.5)$ & $170(39.5)$ & $\begin{array}{c}0.44(0.25 \\
2.4)\end{array}$ & $9.3(2.4,11.6)^{* *}$ \\
\hline \multicolumn{5}{|c|}{ EC free of charge could increase the rate of its utilization (515) } \\
\hline Yes & $245(70.2)$ & $104(29.8)$ & 1 & 1 \\
\hline No & $150(90.5)$ & $16(9.5)$ & $0.2(0.1,5.0)$ & $0.3(0.1,1.4)$ \\
\hline \multicolumn{5}{|c|}{ EC is much better than the regular contraceptive methods in preventing unintended pregnancy (515) } \\
\hline No & $174(71.7)$ & $69(28.3)$ & 1 & 1 \\
\hline Yes & $228(83.8)$ & $17(16.2)$ & $0.2(0.1,0.9)$ & $2.4(1.5,7.2)^{* *}$ \\
\hline
\end{tabular}

** show $P$ value of $<0.05$.

and reproductive characteristics. For instance, the proportion of study participants who had heard of ECs was higher in this study (63\%), compared to $49.8 \%$ reported by a study conducted in South Africa [16]. Different kinds of literature attest that EC use is higher among participants who had heard about ECs compared to those who had not. That could be the reason for the higher prevalence of EC use detected in the current study. The difference with the Nigerian study could be due to knowledge difference among the study participants as the proportion of participants who had good knowledge about ECs was higher in this study (58.4\%) compared to the Nigerian's (45.7\%) [17]. It is clear that EC service use is more common among participants who have good knowledge. When we compare the current finding with the study conducted in Ghana, a difference was noted in the composition of participants. In the case of Ghana, all women of reproductive age (15-49 years) were included, while only university students were included in our study. It is true that most of the time sexual intercourse among adolescents/youths is not planned. Hence, they need to take the only option, EC, after they are exposed to unprotected sex. Additionally, university students may have more information and knowledge about ECs than the general reproductive age women. Moreover, the proportion of married women in Ghana's study was higher (84.5\%) [15] than the $12.8 \%$ in the current study. Married women usually use maintenance contraceptives rather than ECs.

Our finding is greater than those of studies conducted in Ethiopia: Adama University 26.7\% [19], Arba Minch college students $2.7 \%$ [26], Addis Ababa University 4.9\% [20, 21], Hawassa University $10.8 \%$ [23, 32], Mekelle University $24.2 \%[25,33]$, and Wachamo University $44.4 \%$ [24]. This discrepancy might be due to some differences, like time gap among the studies, level of knowledge, and some reproductive characteristics.

For instance, when we look at Adama University, the proportion of study participants who had good knowledge on ECs was $27.2 \%$ [19] which was lower than the $58.4 \%$ of the current study. Having good knowledge about ECs may increase service utilization. In addition, the proportion of students who had used modern contraceptives at Adama University was $10.7 \%$ [19] which was lower than the $20 \%$ of this study. Besides, those who had previous history of contraceptive use may have better knowledge and may develop a positive attitude towards EC. The difference from the study conducted at Hawassa University might be the difference in the proportion of unmarried participants which was higher $(87.2 \%)$ in this study [23]. As married undergraduates usually have regular sexual intercourse, they tend to use maintenance contraceptives rather than ECs. 
The proportion of married participants who had good knowledge about ECs was $58.4 \%$ in our work and $21.9 \%$ in the study on Arba Minch college students [26]. Moreover, the proportion of participants who had heard about ECs in the Arba Minch study was 42.5\% [26], which was lower than the $63 \%$ of the current study. Having information and good knowledge about ECs might increase service utilization. Furthermore, there was a time gap ( 5 years) between the two studies that might have created a difference in the level of information and knowledge on ECs.

The proportion of participants who had sexual intercourse in the study conducted at Arba Minch University was $31.4 \%$ which was lower than the $38.8 \%$ noted in this work [25]. As the proportion of participants who were sexually active at the moment increased, their demand and use of EC also rose. Furthermore, the proportion of participants who had good attitude towards EC was 50.2\% [25] which is lower than the $58.4 \%$ of the current study. Having good attitude towards EC may increase service utilization.

In general, the prevalence of EC use in this study is much higher than national and international reports. The possible reasons for this high report of EC use are discussed here. At Arba Minch University SRH is given as a common course to all first-year undergraduates in addition to the activities of youth health clubs and minimedia on campus. Moreover, student clinics were well equipped and service at the clinics was provided by trained nurses with special training on youth-friendly health services. We believe that the reasons above are the main interventions that could raise EC use and the level of knowledge among university students.

This study also showed that EC utilization was around six and half times more common among participants who had information about ECs than those who had not. This finding is consistent with the findings of studies conducted at Adama University [19], in Adwa town [18], on Arba Minch college students [26], at Mekelle University [25], and at Wachamo University [24], and a study conducted on female clients of the Ethiopian Immigration and Nationality Affairs Office [22]. This could be because having enough information and knowledge about EC might be associated with its use.

Participants who believed that taking EC after unprotected sex for the purpose of preventing unintended pregnancy was a better method than using regular contraceptive methods were two and half times more likely to use the method compared to those who did not. This finding is in line with that of a study conducted in Adwa [18], where previous use of regular contraceptives was a significant predictor of no use of EC. A possible explanation might be that regular users of contraceptive methods might develop a poor attitude for EC as a method of preventing unwanted pregnancy once they develop a habit of using regular contraception.

The treatment approach of EC service providers was also found to be significantly associated with EC utilization. Those who were well approached by EC service providers were around nine times more likely to use ECs than their counterparts. This finding was in line with that of a study conducted at Adama University [19], where inconvenient service delivery was pointed out as the main reason for the no use of EC. It is clear that a good approach by family planning service providers (including EC service providers) encourages service users. The limitation of this study is that the nature of the study design does not reflect casual relationships. Social desirability bias is the possible source of bias that may affect the result of the study. To minimize the impact of social desirability bias, the authors used measures, like recruiting data collectors who were not instructors of the university and using self-administered questionnaire instead of interviewer administered one.

\section{Conclusion}

The prevalence of EC use detected in this study was comparatively higher than those of previous studies conducted in Africa and other Ethiopian universities. Factors found to be associated with EC use were information about ECs, treatment approach of healthcare providers, and attitude towards ECs. Continuing support for and wider dissemination of the class are recommended. The fact that the students/participants readily accepted the preceding provisions made such positive findings possible and sustainable.

\section{Abbreviations \\ AAU: Addis Ababa University \\ AMU: Arba Minch University \\ AOR: Adjusted odds ratio \\ CI: Confidence interval \\ EC: Emergency contraception \\ ECs: Emergency contraceptives \\ ESOG: Ethiopian Society of Obstetricians and Gynecologists \\ FGAE: Family Guidance Association of Ethiopia \\ IUD: Intrauterine device \\ SRH: Sexual and Reproductive Health \\ SPSS: Statistical Package for Social Science Students.}

\section{Conflicts of Interest}

There are no conflicts of interest regarding the publication of this paper.

\section{Authors' Contributions}

Yohannes Ayanaw Habitu, Hedija Yenus Yeshita, Abel Fekadu Dadi, and Desta Galcha were involved in study conception, design, coordination, data collection, data analysis, interpretation, and write-up. Yohannes Ayanaw Habitu prepared the manuscript. All authors read and approved the final manuscript.

\section{Acknowledgments}

The authors would like to acknowledge all the study participants, the data collectors, supervisors, and authorities of AMU, UoG, and IPH for participation in the study and ethical approval. 


\section{References}

[1] L. S. Neinstein, Adolescent Health Care: A Practical Guide, vol. 414, Lippincott Williams \& Wilkins, 2008.

[2] G. Barker, C. Ricardo, and M. Nascimento, Organization WH: Engaging men and boys in changing gender-based inequity in health: Evidence from programme interventions. 2007.

[3] A. A. Olukoya, A. Kaya, B. J. Ferguson, and C. AbouZahr, "Unsafe abortion in adolescents," International Journal of Gynecology and Obstetrics, vol. 75, no. 2, pp. 137-147, 2001.

[4] R. Dixon-Mueller and A. Germain, "Fertility regulation and reproductive health in the millennium development goals: The search for a perfect indicator," American Journal of Public Health, vol. 97, no. 1, pp. 45-51, 2007.

[5] D. Wulf, Sharing responsibility: women society and abortion worldwide. 1999.

[6] A. Thomas, "Policy solutions for preventing unplanned pregnancy," Center on Children and Families Brief, vol. 47, 2012.

[7] S. Singh and J. E. Darroch, "Adding it up: Costs and benefits of contraceptive services," Guttmacher Institute and UNFPA, 2012.

[8] Federal Ministry of Health: Technical and procedural guideline for safe abortion services in Ethiopia. Addis Ababa, Ethiopia. 2006.

[9] J. Cleland, S. Bernstein, A. Ezeh, A. Faundes, A. Glasier, and J. Innis, "Family planning: the unfinished agenda," The Lancet, vol. 368, no. 9549, pp. 1810-1827, 2006.

[10] Ethiopian Society of Obstetricians and Gynecologists (ESOG), $\mathrm{MoHF}$, and ECafrique, "A training curriculum for mid-level health workers in Ethiopia. Addis Ababa, Ethiopia," vol. 1, no. 2, 2005.

[11] The federal Democratic Republic of Ethiopia: The criminal code of conduct of the Federal Democratic Republic of Ethiopia. Proclamation No. 414/2004. 2005.

[12] J. Beitz and J. Hutchings, "Beyond Our Borders: Emergency contraception: A vital component of reproductive health programs," Western Journal of Medicine, vol. 176, no. 3, pp. 152-154, 2002.

[13] ICEC: EC Status and Availability Database. http://www .cecinfo.org/country-by-country-information/status-availability-database/countries/ethiopia/.

[14] S. Subedi, "Knowledge, attitude and practice of emergency contraceptive among the youth of Parbat District," Journal of Health and Allied Sciences, vol. 2, no. 1, pp. 50-53, 2012.

[15] A. Amalba, V. Mogre, M. N. A. Appiah, and W. A. Mumuni, "Awareness, use and associated factors of emergency contraceptive pills among women of reproductive age (15-49 years) in Tamale, Ghana," BMC Women's Health, vol. 14, no. 1, article no. 114, 2014.

[16] M. E. Hoque and S. Ghuman, "Knowledge, practices, and attitudes of emergency contraception among female university students in KwaZulu-Natal, South Africa," PLoS ONE, vol. 7, article e46346, no. 9, 2012.

[17] I. Ezebialu and A. Eke, "Knowledge and practice of emergency contraception among female undergraduates in South Eastern Nigeria," Annals of Medical and Health Sciences Research, vol. 3, no. 4, pp. 541-545, 2013.

[18] G. Miruts, D. Yeman, and K. Abera, "Factors associated with emergency contraceptive use among female preparatory schools students Adwa Town, Northern Ethiopia," International Journal of Pharmaceutical Sciences and Research (IJPSR), 2013.
[19] F. D. Tilahun, T. Assefa, and T. Belachew, "Predictors of emergency contraceptive use among regular female students at Adama University, Central Ethiopia.", The Pan African Medical Journal, vol. 7, p. 16, 2010.

[20] W. Tamire and F. Enqueselassie, "Knowledge, attitude, and practice on emergency contraceptives among female university students in Addis Ababa, Ethiopia," Ethiopian Journal of Health Development, vol. 21, no. 2, pp. 111-116, 2007.

[21] F. A. Ahmed, K. M. Moussa, K. O. Petterson, and B. O. Asamoah, "Assessing knowledge, attitude, and practice of emergency contraception: A cross-sectional study among Ethiopian undergraduate female students," BMC Public Health, vol. 12, no. 1, article 110, 2012.

[22] G. Bugssa, T. Kahsay, A. Asres et al., "Factors associated with knowledge, attitude and practice towards emergency contraception among female clients of Ethiopian Immigration and Nationality Affairs Office," Journal of Community Medicine \& Health Education, vol. 04, article 1000305, no. 305, pp. 2161-2711, 2014.

[23] E. Tolossa, B. Meshesha, and A. Alemu Abajobir, "Assessment of level of knowledge and utilization of emergency contraception among female students of Hawassa University, south Ethiopia," Advances in Reproductive Sciences, vol. 01, no. 03, pp. 51-56, 2013.

[24] T. G. Hailemariam, T. Tesfaye, T. Melese et al., "Sexual experiences and emergency contraceptive use among female university students: A cross-sectional study at Wachamo University, Ethiopia Public Health," BMC Research Notes, vol. 8, no. 1, article no. 112, 2015.

[25] H. Gebrehiwot, B. Gebrekidan, H. Berhe, and K. Kidanu, "Assessment of knowledge, attitude, and practice towards emergency contraceptives among female college students at Mekelle town, Tigray region, Ethiopia: A Cross sectional study," International Journal of Pharmaceutical Sciences and Research, vol. 4, no. 3, 1027 pages, 2013.

[26] A. Worku, "Knowledge, attitude and practice of emergency contraceptives among female college students in Arba Minch town, Southern Ethiopia," Ethiopian Journal of Health Development, vol. 25, no. 3, pp. 176-183, 2012.

[27] G. Aluzimbi, J. Barker, R. King et al., "Risk factors for unplanned sex among university students in Kampala, Uganda: A qualitative study," International Journal of Adolescence and Youth, vol. 18, no. 3, pp. 191-203, 2013.

[28] T. S. Mengistu and A. T. Melku, "Sexual and reproductive health problems and service needs of university students in South East Ethiopia: Exploratory qualitative study," Science Journal of Public Health, vol. 1, no. 4, 2013.

[29] S. Mitiku, M. Demissie, F. Belayneh, and M. M, "Prevalence of induced abortion and associated factors among wachamo university regular female students, Southern Ethiopia," Journal of Health Medicine and Nursing, vol. 21, 2015.

[30] A. Unasho and T. Tadesse, "Assessment of potential risky sexual behaviors among Dilla University students: A survey study for enhancing self- protection from human immunodeficiency virus (HIV) infection," Journal of AIDS and HIV Research, vol. 5, no. 7, 2013.

[31] University AM: Arbaminch University profile. http://www .integranet.amu., 2015.

[32] B. Wondimu, Emergency Contraceptive: Post-Secondary School Female Students'and Service Providers'perspective (The Case of Awassa Town), 2008. 
[33] G. B. Abera, B. Berhanu, A. B. Kahsay, and H. B. Gebru, "Assessment of determinants of induced abortion among child bearing age women attending maternal and child health clinic in Mekelle town, Tigray, Ethiopia: a cross sectional study," International Journal of Pharmaceutical Sciences and Research, vol. 3, no. 12, pp. 45-47, 2012. 


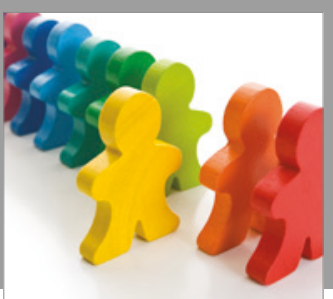

Autism

Research and Treatment
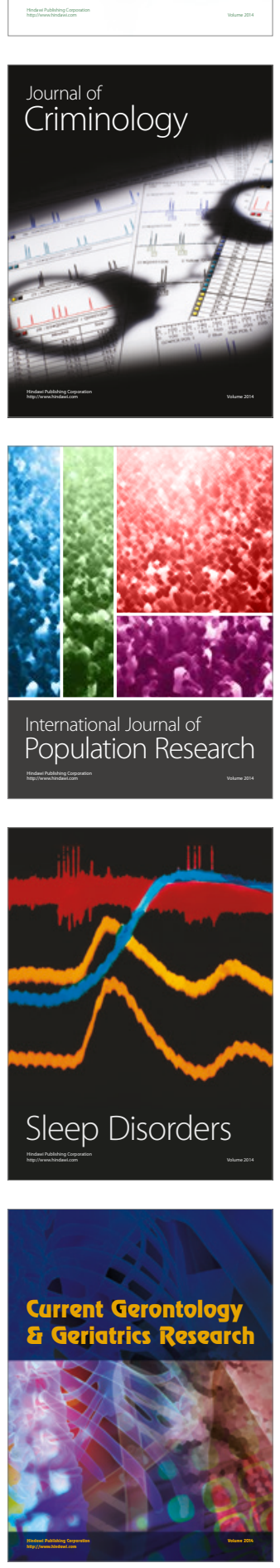

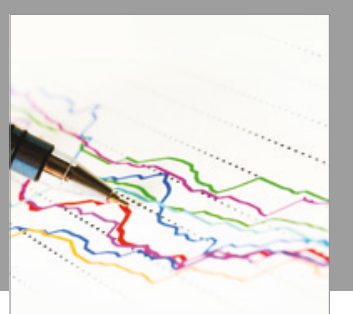

Economics

Research International

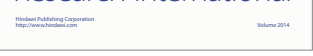

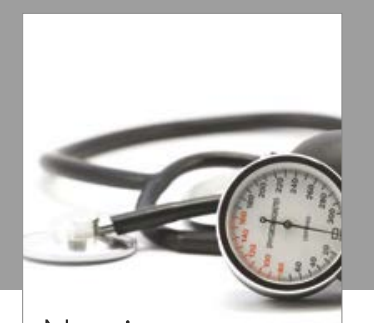

Nursing

Research and Practice

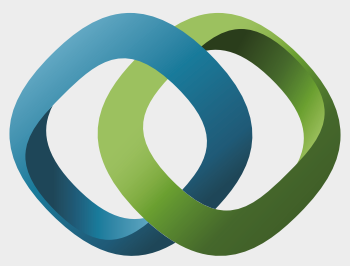

\section{Hindawi}

Submit your manuscripts at

https://www.hindawi.com
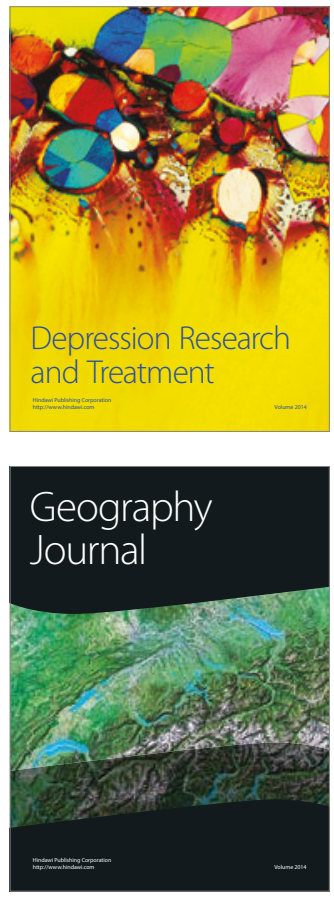
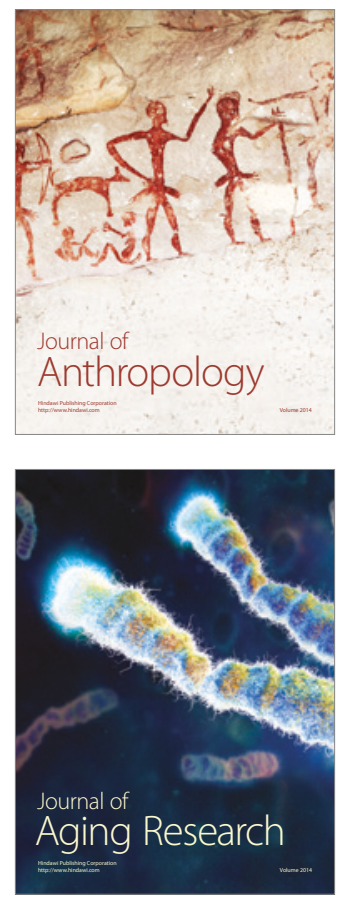
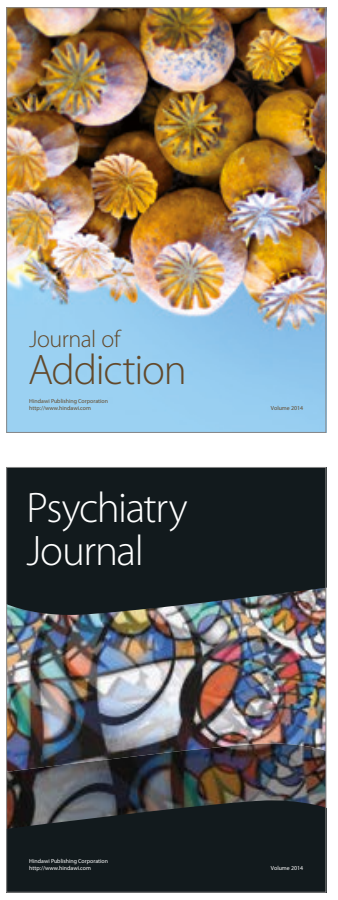

Child Development

Research

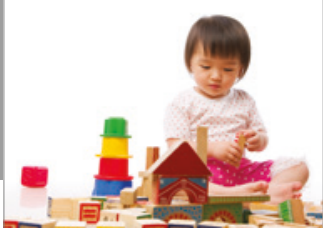

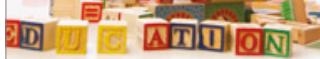
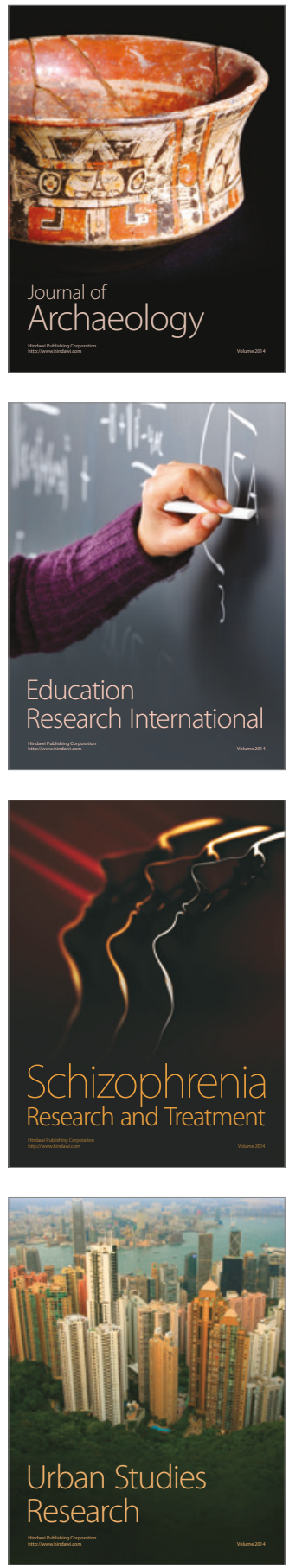